of the European Seismological Commission, has produced the first draft of a seismo-tectonic map of Europe, and other maps of a somewhat similar character have been produced for other countries and regions of the world. Dr. Hodgson gives maps for Canada and the United States in his book.

For ongineers dealing with earthquake-rosistant design, a knowledge of the maximum earthquake intensity likely to be encountered in any locality is only a beginning. Strain seismographs ean indicate present trends, strong motion seismographs can record accelerations and periods, and from shaking-table experiments much can be learned since the shaking may now be made to simulate actual earth movement during the earthquake for which seismograms are available. In some areas of the world building codes ars absolutely essential. Moreover, since the advent of atomic power stations into areas likely to be affected by earthquakes, the problem has become much more acute. In recent years in Britain a seismic engineering group has been formed. This would have delighted John Milne, the 'founder' of British seismology and, through the British Association for the Advancement of Science, the originator of the project of a world-wide network of unified seismograph stations; for Milne was a British professor of engineering in Japan, turned seismologist. Dr. Hodgson in his book deals with the North American attack on these problems.

Dr. Hodgson's book will prove a most valuable introduction to the observation of earthquakes for all who wish for a non-mathematical approach. It cannot fail to be interesting and informative, and the only drawback in Britain is the price; 24s. is rather expensive for a paper-back of 175 pages.

E. Tillotson

\section{A CHAPTER OF CHEMISTRY}

\section{Man-Made Transuranium Elements}

By Prof. Glenn T. Seaborg. (Foundations of Modern General Chemistry Series.) Pp. viii +120 . (Englewood Cliffs, N.J.: Prentice-Hall, Inc., 1963.) 12s. paper; $32 s$. cloth.

JO part of chemistry, not even a paragraph, is ever complete; but this important chapter has now reached a stage whore further developments can be expected to be more in the nature of refinements to the style, than exciting new changes or additions to the text.

Most books are written for a readily identifiable readership, first- and second-year university texts, authoritative monographs for research workers and a number of other clearly defined categories. It is pleasant to read a scientific work that avoids this classification. Man-Made Transuranium Elements was written as a consequence of the author's interest in the Chemical Educational Material Study Group in California. One presumes that it is intended, in part, for the moro gifted secondary or highschool student. Although it would be surprising if many such students, even in California, could really understand everything in the book, it is certainly true that they would both profit from and enjoy reading it.

The author and the subject are so related that the book has a strongly autobiographical flavour. Never obtrusive, these touches heighten the reality of the historical sequences in the book and convey much of the excitement that was felt during many of these remarkable discoveries.

The story is unique; eleven man-made elements produced and identified in twenty-odd years, many of these in Prof. Seaborg's laboratory. But the proliferation of the elements, though interesting, is not the most important scientific aspect of these achievements. Now that one begins to read this chapter in the context of the rest of the developments in chemistry, it is, perhaps, possible to begin to pick out the most significant features.
First, the key to the identification of the later members of the group, the demonstration that these elements constitute a new sorics in which the $5 f$ orbitals are being filled. Such a series had long been predicted, even in such details as its differences from the lanthanide elements; but, as ever, the facts, while broadly confirming these predictions, threw up a host of new problems. Some of these, such as the unusual crystal structures and properties of the elemental forms of these metallic elements, are still unresolved.

The earlier investigations of the first five or six trans. uranic elements were a triumph for microchemical techniques. The tetrad, uranium, neptunium, plutonium and americium, with their several valencies has provided inorganic chemistry with a rich field of investigation for many years to come. The difficulty of the separation of these elements, especially those of the highest atomic number, has led directly to a much deeper knowledge of the processes of ion exchange and solvent extraction. Indeed, it is clear that, but for the close analogy between the ion-exchange behaviour of the actinide and lanth. anide elements, it is unlikely that the elements of greater atomic number than curium would have been characterized so quickly. Present-day knowledge of their chemistry amounts to little more than their ion-exchange characteristies.

Besides these important purely chemical results, the production and investigation of the transuranium elements have yielded a rich reward of nuclear chemical information. A large part of our knowledge of fission derives from observations of isotopes of these elements.

The accumulation of a substantial body of fairly reliable data on the nuclear characteristics of the numerous isotopes of these elements revealed a number of these systematic features of nuclcar stability, and this provided one of the lines of evidence on which our knowledge of nuclear forces has developed.

Some years ago, the present director of the Atomic Energy Research Establishment, Dr. R. Spence, proposed to me a measure of the importance of developments in natural science which is easily applied and generally reliable. The really important developments are those that, within two or three years, demand inelusion in the undergraduate courses. By this yardstick, this chapter of chemistry does indeed include a number of developments of fundamental importance. A. G. MADDOCK

\section{INSTRUMENTATION FOR CHEMICAL ANALYSIS}

\section{Analysis Instrumentation-1963}

Edited by Dr. L. Fowler, R. D. Eanes, and T. J. Kehoe. (Proceedings of the Ninth National Analysis Instrumentation Symposium held April 29-May 1, 1963, at Houston, Texas.) Pp. $\mathrm{x}+261$. (Pittsburgh, Pa.: Instrument Society of America, 1963. Distributed by Plenum Press, New York.) 12.50 dollars.

$A^{\mathrm{s}}$ the bibliographic particulars indicate, this volume contains papers read at a symposium, and it follows the usual pattern, covering a very wide field. Unlike the Proceedings of earlier symposia of this series, the book is bound in hard covers.

There are thirty individual papers grouped under six headings :

"Keynote Session-Analysis Instrumentation Today" deals with the present status of analysis instrumentation from the point of view of the manufacturer, user and developer, and is discursive and non-detailed. Three pages devoted to humorous and apt cartoons enliven this section.

"Dynamies of Analysis Instruments" is concerned with detailed design of instruments for the control of dynamic 